\title{
Training Working Memory: Anatomy Matters
}

\author{
(-Alexander J. Simon, Sasha N. Skinner, and David A. Ziegler \\ Department of Neurology, University of California, San Francisco 94158 \\ Review of Ekman et al.
}

Working memory (WM) is the ability to select and hold online goal-relevant information for a short time (i.e., seconds). The ability to manage the barrage of sensory inputs that we encounter allows us to engage in complex, goal-directed behavior. Thus, WM is considered a fundamental component of virtually all aspects of high-order cognition, and is supported by a widely distributed network of connections between the frontal and parietal lobes and more posterior sensory cortices (Miller and Cohen, 2001). It is well established that individual WM capacities are highly variable (Luck and Vogel, 2013) and some evidence suggests that white matter integrity in frontoparietal regions is linked to WM capacities (Darki and Klingberg, 2015). Less clear is how individual differences in frontoparietal white matter integrity contribute to differences in WM capacity.

Recently in The Journal of Neuroscience, Ekman et al. (2016) tested the hypothesis that there are two distinct anatomical pathways that connect prefrontal to posterior parietal regions and that each pathway supports a different component of WM. The first pathway, a direct corticocortical connection via the superior longitudinal fasciculus, was hypothesized to be responsible for maintaining information in WM. A second indirect pathway connecting prefrontal and

Received May 9, 2016; revised June 16, 2016; accepted June 21, 2016. The authors declare no competing financial interests.

Correspondence should be addressed to Dr. David A. Ziegler University of California, San Francisco Sandler Neurosciences Center, $675 \mathrm{Nel}-$ son Rising Lane, UCSF MC 0444, San Francisco, CA 94158. E-mail: david.ziegler@ucsf.edu.

DOI:10.1523/JNEUROSCI.1513-16.2016

Copyright $\odot 2016$ the authors $\quad 0270-6474 / 16 / 367805-02 \$ 15.00 / 0$ posterior parietal regions via the striatum was predicted to support the flexibility to update the contents held in WM.

The authors designed two separate studies to investigate the neural mechanisms supporting these distinct types of WM. The WM tasks in both experiments required participants to maintain digits in WM. Study 1 also required that participants modify the digits held in WM, which the authors predicted would be supported by a different neural pathway than simple maintenance of items in WM. In Study 1 participants were presented with $2-7$ numbers on a $3 \times 3$ grid. Participants held those numbers in WM and then either added or subtracted 1 to each number, as indicated by an up or down arrow. In contrast, for Study 2, participants were only required to maintain a sequence of 2-10 verbally presented digits in WM.

To assess individual differences in white matter structure, Ekman et al. (2016) used high-resolution MRI data to generate individual connectomes for each participant with whole-brain probabilistic tractography. Individual connectivity matrices were then generated and were used to measure network centrality, a quantitative measure of the connectivity strength of each node in a network. The authors then compared these graph theoretic metrics with WM capacity on the two tasks. In both experiments, network centrality in the right lateral prefrontal cortex was significantly correlated with individual WM capacity. For Study 2, which only required participants to maintain items in WM, WM capacity was also significantly correlated with network centrality in the left frontoparietal operculum, extending to the superior temporal gyrus.

The authors used this overlap in the statistical maps as ROIs to perform anatomically constrained probabilistic tractography for both studies and then estimated the connectivity between the PFC and posterior parietal cortex via the direct and indirect pathways. Critically, this analysis revealed that the direct and indirect pathways showed distinct patterns of correlation with WM capacity, suggesting that the pathways support separable components of WM. Specifically, there was a positive association between both the direct and indirect pathways and WM capacity in Study 1, in which participants were asked to manipulate information in WM, whereas only the direct pathway was significantly correlated with WM capacity in Study 2, which only required participants to hold information online. These results support the notion that the indirect pathway specifically supports the ability to manipulate the contents of WM, whereas the direct pathway supports WM regardless of whether its contents are manipulated.

The results of the Ekman et al. (2016) study may shed important new light on a rapidly growing area of translational neuroscience: cognitive training. Specifically, there has been tremendous interest in WM training as a potential treatment for children with attention deficit hyperactivity disorder (ADHD), either as a primary or adjunctive therapy (Klingberg et al., 2005; Cortese et al., 2015). There is evidence that WM deficits underlie core behavioral inhibition deficiencies in ADHD (Alderson et 
al., 2010), and poor WM in ADHD is associated with increased risk of academic deficits and cognitive dysfunction (Fried et al., 2016). Thus, in theory, strengthening WM in children with ADHD should lead to widespread improvements in core neuropsychological domains, such as attention, inhibition, and reasoning, as well as in behavioral symptoms and academic performance (Engle et al., 1999; Cortese et al., 2015). In practice, however, most cognitive training interventions have had relatively limited successes in improving behaviors outside the narrow domain of cognitive control that was specifically trained.

A number of randomized controlled trials have examined the effects of WM training in children with ADHD (Klingberg et al., 2005; Beck et al., 2010; Green et al., 2012; Egeland et al., 2013; Hovik et al., 2013; van Dongen-Boomsma et al., 2014). Several of these studies showed that the trained groups experienced WM gains (Klingberg et al., 2005; Green et al., 2012; Hovik et al., 2013; van Dongen-Boomsma et al., 2014). At the same time, these studies have consistently failed to report improvements in key ADHD symptoms, such as behavior at home and in school, academic performance, and performance on cognitive tasks that assess attention, inhibition, and executive functioning (Cortese et al., 2015).

Importantly, other research suggests that WM manipulation, more than maintenance, appears to be fundamental to many cognitive deficits in ADHD (Fried et al., 2016) and is associated with dysfunction in frontostriatal circuits (Martinussen et al., 2005). The findings of Ekman et al. (2016) provide further insight into the potential neural mechanisms underlying this deficit and raise the possibility that past WM training studies have failed to show transfer to improvements in ADHD symptoms because the WM training programs were primarily designed to improve WM capacity without challenging other aspects of WM, such as monitoring, updating, and manipulating, to the same degree. Thus, the lack of consistent improvements in other cognitive and behavioral domains could be because the training most likely engaged the direct fronto-parietal pathway to a greater extent than the indirect fronto-striatal-parietal pathway identified by Ekman et al. (2016). Indeed, one study found improvements in WM manipulation in tasks that require WM content updating as a result of their training (Hovik et al., 2013), which indicates that frontostriatal-parietal networks were trained to some degree.

Further evidence supporting the benefits of training multiple WM pathways comes from a recent meta-analysis of WM training interventions in children with ADHD (Cortese et al., 2015). Although most studies showed little evidence of far transfer to changes in behaviors like hyperactivity and impulsivity, or to improvements on standardized tests of academic ability, the few studies that used a "multiple-process" approach showed the greatest impact on overall ADHD symptomatology. This finding parallels an emerging approach being adopted by a growing field of translational neuroscientists who are attempting to harness the power of videogames to create highly engaging, interactive, and rewarding cognitive training paradigms that push participants to strengthen cognition across multiple domains (Mishra et al., 2016). This approach has yielded powerful changes in both cognition and underlying neural activity in healthy older adults (Anguera et al., 2013) and has the potential to do the same for children with ADHD. Given this new knowledge of how underlying white matter networks correlate with different aspects of WM, designing a newer generation of WM training games that challenge multiple domains of WM and use an immersive videogame format might have the potential to yield truly effective nonpharmacological therapies for ADHD. Future studies of WM training in children with ADHD should challenge their ability to flexibly update the contents of WM to engage, and in turn strengthen, indirect frontostriatalparietal pathways and should include neuroimaging as outcome measures to test whether such training leads to structural changes in this pathway.

\section{References}

Alderson RM, Rapport MD, Hudec KL, Sarver DE, Kofler MJ (2010) Competing core processes in attention-deficit/hyperactivity disorder (ADHD): do working memory deficiencies underlie behavioral inhibition deficits? J Abnorm Child Psychol 38:497-507. CrossRef Medline

Anguera JA, Boccanfuso J, Rintoul JL, Al-Hashimi O, Faraji F, Janowich J, Kong E, Larraburo Y, Rolle C, Johnston E, Gazzaley A (2013) Video game training enhances cognitive control in older adults. Nature 501:97-101. CrossRef Medline

Beck SJ, Hanson CA, Puffenberger SS, Benninger KL, Benninger WB (2010) A controlled trial of working memory training for children and adolescents with ADHD. J Clin Child Adolesc Psychol 39:825-836. CrossRef Medline

Cortese S, Ferrin M, Brandeis D, Buitelaar J, Daley D, Dittmann RW, Holtmann M, Santosh P, Steven- son J, Stringaris A, Zuddas A, Sonuga-Barke EJ (2015) Cognitive training for attention-deficit/ hyperactivity disorder: meta-analysis of clinical and neuropsychological outcomes from randomized controlled trials. J Am Acad Child Adolesc Psychiatry 54:164-174. CrossRef Medline

Darki F, Klingberg T (2015) The role of frontoparietal and fronto-striatal networks in the development of working memory: a longitudinal study. Cereb Cortex 25:1587-1595. CrossRef Medline

Egeland J, Aarlien AK, Saunes BK (2013) Few effects of far transfer of working memory training in ADHD: a randomized controlled trial. PLoS One 8:e75660. CrossRef Medline

Ekman M, Fiebach CJ, Melzer C, Tittgemeyer M, Derrfuss J (2016) Different roles of direct and indirect frontoparietal pathways for individual working memory capacity. J Neurosci 36:2894-2903. CrossRef Medline

Engle RW, Tuholski SW, Laughlin JE, Conway AR (1999) Working memory, short-term memory, and general fluid intelligence: a latentvariable approach. J Exp Psychol Gen 128: 309-331. CrossRef Medline

Fried R, Chan J, Feinberg L, Pope A, Woodworth KY, Faraone SV, Biederman J (2016) Clinical correlates of working memory deficits in youth with and without ADHD: a controlled study. J Clin Exp Neuropsychol 38:487-496. CrossRef Medline

Green CT, Long DL, Green D, Iosif AM, Dixon JF, Miller MR, Fassbender C, Schweitzer JB (2012) Will working memory training generalize to improve off-task behavior in children with attention-deficit/hyperactivity disorder? Neurotherapeutics 9:639-648. CrossRef Medline

Hovik KT, Saunes BK, Aarlien AK, Egeland J (2013) RCT of working memory training in ADHD: long-term near-transfer effects. PLoS One 8:e80561. CrossRef Medline

Klingberg T, Fernell E, Olesen PJ, Johnson M, Gustafsson P, Dahlström K, Gillberg CG, Forssberg H, Westerberg H (2005) Computerized training of working memory in children with ADHD: a randomized, controlled trial. J Am Acad Child Adolesc Psychiatry 44: 177-186. CrossRef Medline

Luck SJ, Vogel EK (2013) Visual working memory capacity: from psychophysics and neurobiology to individual differences. Trends Cogn Sci 17:391-400. CrossRef Medline

Martinussen R, Hayden J, Hogg-Johnson S, Tannock R (2005) A meta-analysis of working memory impairments in children with attention-deficit/ hyperactivity disorder. J Am Acad Child Adolesc Psychiatry 44:377-384. CrossRef Medline

Miller EK, Cohen JD (2001) An integrative theory of prefrontal cortex function. Annu Rev Neurosci 24:167-202. CrossRef Medline

Mishra J, Anguera JA, Gazzaley A (2016) Video games for neuro-cognitive optimization. $\mathrm{Ne}$ uron 90:214-218. CrossRef Medline

van Dongen-Boomsma M, Vollebregt MA, Buitelaar JK, Slaats-Willemse D (2014) Working memory training in young children with ADHD: a randomized placebo-controlled trial. J Child Psychol Psychiatry 55:886-896. CrossRef Medline 